\title{
BMJ Open Household sanitation and personal hygiene practices are associated with child stunting in rural India: a cross-sectional analysis of surveys
}

\author{
Jee Hyun Rah, ${ }^{1}$ Aidan A Cronin, ${ }^{2}$ Bhupendra Badgaiyan, ${ }^{1}$ Victor M Aguayo, ${ }^{3}$ \\ Suzanne Coates, ${ }^{4}$ Sarah Ahmed ${ }^{5}$
}

To cite: Rah JH, Cronin AA, Badgaiyan $\mathrm{B}$, et al. Household sanitation and personal hygiene practices are associated with child stunting in rural India: a cross-sectional analysis of surveys. BMJ Open 2015;5: e005180. doi:10.1136/ bmjopen-2014-005180

- Prepublication history for this paper is available online To view these files please visit the journal online (http://dx.doi.org/10.1136/ bmjopen-2014-005180)

Received 4 March 2014 Revised 16 September 2014 Accepted 17 September 2014

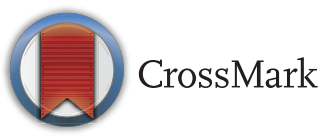

For numbered affiliations see end of article.

Correspondence to Dr Jee Hyun Rah; jhrah@unicef.org

\section{ABSTRACT}

Objectives: Increasing evidence suggests that water, sanitation and hygiene (WASH) practices affect linear growth in early childhood. We determined the association between household access to water, sanitation and personal hygiene practices with stunting among children aged 0-23 months in rural India.

Setting: India.

Participants: A total of 10364,34639 and 1282 under-2s who participated in the 2005-2006 National Family Health Survey (NFHS-3), the 2011 Hunger and Malnutrition Survey (HUNGaMA) and the 2012 Comprehensive Nutrition Survey in Maharashtra (CNSM), respectively, were included in the analysis.

Primary outcome measures: The association between WASH indicators and child stunting was assessed using logistic regression models.

Results: The prevalence of stunting ranged from $25 \%$ to $50 \%$ across the three studies. Compared with open defecation, household access to toilet facility was associated with a $16-39 \%$ reduced odds of stunting among children aged 0-23 months, after adjusting for all potential confounders (NHFS-3 $(\mathrm{OR}=0.84,95 \% \mathrm{Cl} 0.71$ to 0.99$)$; HUNGaMA (OR=0.84, 95\% Cl 0.78 to 0.91 ); CNSM (OR=0.61, $95 \% \mathrm{Cl} 0.44$ to 0.85$)$ ). Household access to improved water supply or piped water was not in itself associated with stunting. The caregiver's self-reported practices of washing hands with soap before meals (OR=0.85, 95\% Cl 0.76 to 0.94 ) or after defecation $(\mathrm{OR}=0.86,95 \% \mathrm{Cl} 0.80$ to 0.93 ) were inversely associated with child stunting. However, the inverse association between reported personal hygiene practices and stunting was stronger among households with access to toilet facility or piped water (all interaction terms, $\mathrm{p}<0.05$ ).

Conclusions: Improved conditions of sanitation and hygiene practices are associated with reduced prevalence of stunting in rural India. Policies and programming aiming to address child stunting should encompass WASH interventions, thus shifting the emphasis from nutrition-specific to nutrition-sensitive programming. Future randomised trials are warranted to validate the causal association.

\section{Strengths and limitations of this study}

- We analysed three large survey data sets collected at the household level and representative of different administrative units: national, state and district.

- We analysed cross-sectional data, so a causal association between improved water, sanitation and hygiene practices and reduced likelihood of stunting cannot be established.

- The mothers'/caregivers' reported personal hygiene practices were determined based on self-reported data.

\section{INTRODUCTION}

In 2012, the WHO adopted a new global target of reducing the number of stunted children under 5 by $40 \%$ by $2025 .^{1}$ Despite over two decades of significant economic growth, India has one of the world's highest child stunting rates. The 2006 National Family Health Survey (NFHS-3) shows that $48 \%$ of Indian children under 5-61 million children-are stunted due to chronic nutrition deprivation, accounting for more than one-third of stunted children in the developing world. ${ }^{2}$ Child stunting is linked to serious and largely irreversible consequences for survival, health, development, school performance and productivity in adult life. ${ }^{3} 4$

For many children, stunted growth starts before birth as a result of poor maternal nutritional status and worsens gradually during the first 2 years of life. ${ }^{5}$ Thus, the first 1000 days, from conception until the age of 2 years, are a critical window of opportunity, during which timely interventions can have a measurable and lasting impact on the prevention of child stunting. ${ }^{2}$ Importantly, however, in the current context of widespread infection and contamination in 
children's environments, dietary interventions alone may be insufficient to promote optimal growth in children in developing countries. In such environments, efficacy studies with nutrient-dense food supplements have shown to improve child linear growth only by 0.7 height-for-age z-score at best. ${ }^{6}$ This reflects on only one-third of the average height deficit in South Asian and sub-Saharan African children. ${ }^{7}$

Growing evidence suggests a link between child linear growth and household water, sanitation and hygiene (WASH) practices. ${ }^{8}$ It has previously been estimated that as much as $50 \%$ of child undernutrition may be attributable to poor WASH practices. ${ }^{9}$ Ingestion of high quantities of faecal bacteria from both human and animal sources by infants and young children through mouthing soiled fingers and household items, and the exploratory ingestion of soil and poultry faeces are common in many rural low-income environments. This leads to intestinal infections which affect a child's nutritional status by diminishing appetite, impairing nutrient absorption and increasing nutrient losses. ${ }^{10}$

In India, approximately 53\% of households and 624 million people defecate in the open. ${ }^{2}$ Open defecation is more pervasive in rural versus urban areas $(74 \%$ vs $17 \%)$. Recently, an ecological analysis of data from 112 rural districts of India demonstrated a strong association between the prevalence of open defecation and stunting, after adjusting for potential confounders. ${ }^{11}$ This analysis added to a growing body of suggestive evidence on the effect of open defecation on child linear growth. However, further evidence is needed to corroborate the findings, as ecological studies are prone to ecological fallacy and other errors, and are often used to generate hypotheses for additional investigation employing more rigorous methods. ${ }^{11}$

Strengthening the evidence base on the linkages between child linear growth and WASH practices in the Indian population will help support the informed development of policy and guidelines that inform optimal programmatic strategies, actions and monitoring. This study therefore sought to determine whether improved WASH conditions are associated with reduced child stunting in rural India. Specifically, the analysis aimed to determine the association between stunting and household access to sanitation facilities, water supply and personal hygiene practices using multiple logistic regression analyses.

\section{METHODS}

Data

We analysed three large data sets obtained from the 2005-2006 NFHS-3, the 2011 Hunger and Malnutrition survey (HUNGaMA) and the 2012 Comprehensive Nutrition Survey in Maharashtra (CNSM). Details of the three surveys are described elsewhere. ${ }^{2}{ }^{12}{ }^{13}$ Briefly, NFHS-3 is a Demographic Health Survey carried out by the International Institute for Population Services (IIPS) in 2005-2006 that provides information on the mortality, fertility, family planning, environmental hygiene, nutrition and health status of India's population. ${ }^{2}$ A stratified multistage cluster sampling method was used to identify a nationally representative sample of India's population living in both urban and rural areas in 29 states. A total of 109041 households were selected, from which a total of 124385 women aged 15-49 years and 74369 men aged $15-54$ years were included in the survey. ${ }^{2}$

The HUNGaMA survey was conducted by the Naandi Foundation in 2011 to collect district level data on the nutritional status of Indian children below 5 years of age. ${ }^{12}$ The survey covered 112 rural districts across nine states in India, namely Bihar, Himachal Pradesh, Jharkhand, Kerala, Madhya Pradesh, Odisha, Rajasthan, Uttar Pradesh and Tamil Nadu. Of these, 100 districts were those with the poorest indicators of child well-being in the country, and the remaining 12 districts were selected among those with some of the best indicators of child well-being for the purpose of within-state comparison. The selected areas represent about one-sixth of India's population and one-fifth of India's children under 5. A stratified cluster sampling was employed to identify a representative sample of 73670 households from which a total of 109903 children under 5 were included in the survey. Information on child nutritional status was collected together with relevant maternal, household and environmental determinants. ${ }^{12}$

CNSM is the first-ever state-specific survey in India that provides information on nutritional status and feeding practices of children below 2 years of age and relevant maternal and household determinants. ${ }^{13}$ It survey is a joint initiative of the Government of Maharashtra and UNICEF, implemented by the IIPS. A multistage stratified sampling method was used to select a total of 2650 children under 2 years of age from 2630 households from the six administrative divisions of the state, namely Amravati, Aurangabad, Konkan, Nagpur, Nashik and Pune. ${ }^{13}$ The sampling scheme was designed to represent Maharashtra State.

These surveys all have different sample sizes as they are representative of different administrative units, national for NFHS and state for CNSM. The HUNGaMA survey represents a spread of the poorest districts in India and has a large sample size with a larger open defecation rate, but one in line with Census data. Ethical approval was not sought for this secondary analysis of publicly available survey data.

\section{Data collection}

Data were collected using similar methods in all three surveys. ${ }^{2} 1213$ All interviews and anthropometric measurements were conducted at home by field teams who visited eligible respondents in each of the selected households. Written consent was sought from each respondent and parents or guardians provided consent for infants and children. Interviews and assessments were carried out only after consent was obtained. 
Information on the child's age, sex, morbidity in the past week(s), immunisation status, breastfeeding practices and dietary intake was collected from the mother of the child or caregiver. Mothers/caregivers were interviewed regarding their age, education, reproductive history, nutritional status, morbidity and reported personal hygiene practices. Information on household composition, source of drinking water and sanitation facility, socioeconomic status, and utilisation of social safety net programmes was also collected. All interviews were carried out using a structured questionnaire.

Anthropometric measurements were taken from the children and mothers following standard procedures. ${ }^{14}$ Height was measured using a height/length board to the nearest $0.1 \mathrm{~cm}$. Weight was assessed using an electronic weight scale to the nearest $0.1 \mathrm{~kg}$. Age of the children was determined using the immunisation cards or home records of date of birth to the extent possible. When these documents were unavailable, the local events calendar was used to help with the recall of the child's age.

The field interviewers/anthropometrists were from local non-governmental organisation partners and were thoroughly trained before data collection. The performance of field staff during data collection was continuously monitored by supervisors and quality control teams who rechecked some of the data the following day to ensure data reliability. Non-response and refusal to participate in the surveys were minimal.

\section{Statistical analysis}

This analysis included 10364,34639 and 1282 children 0-23 months of age in rural India who participated in NFHS-3, HUNGaMA and CNSM, respectively. When more than one child under 2 was assessed in a given household, only the youngest child from each household was included in the analysis. All analyses were weighted according to the population size and adjusted for the multistage cluster design of the surveys.

Stunting and wasting were defined as HAZ and weight-for-height $z$-scores less than 2 , respectively, using the WHO growth standards in AnthroPlus 2009 software. ${ }^{15}$ Maternal body mass index (BMI) was defined as weight divided by the square of height $\left(\mathrm{kg} / \mathrm{m}^{2}\right)$. In the analysis of data obtained from NFHS and CNSM, sources of drinking water were classified into improved water sources including water piped into a dwelling, plot or yard, public tap or standpipe, tube well or borehole, protected dug well, protected spring, and rainwater versus unimproved water. ${ }^{16}{ }^{17}$ Improved sanitation facilities included a flush toilet, piped sewer system, septic tank, flush to pit latrine, ventilated improved pit latrine, pit latrine with slab and composting toilet. ${ }^{16}$ A comparison was also made between piped water versus other sources of drinking water and any toilet facility versus open defecation. The HUNGaMA categorised the source of drinking water only as hand pump and piped water and others and sanitation as defecating in the open versus any toilet. ${ }^{12}$

In NFHS-3 and CNSM, a wealth index was computed as an indicator of household economic status. Details on the estimation of household wealth index are described elsewhere. ${ }^{12}{ }^{13}$ Briefly, each asset was assigned a standardised score generated through a principal components analysis. The selected households were then ranked according to the sum of household asset scores and grouped into five wealth quintiles from the lowest (poorest) to the highest (richest) score. For HUNGaMA, a wealth index was not generated and household ownership of durable assets was used as the primary indicator of household economic status.

Data for each survey were analysed separately. Descriptive statistics were used to examine the distribution of the full range of variables. Using appropriate cut-offs, dichotomous or categorical variables were created for a few variables such as birth order $(1-2,3-4$ or $\geq 5$ ); maternal education (no education, primary school, secondary school or $>$ secondary school); maternal age $(<20,20-29, \geq 30)$; maternal height $(<$ or $\geq 150 \mathrm{~cm})$; maternal BMI $\left(<\right.$ or $\left.\geq 18.5 \mathrm{~kg} / \mathrm{m}^{2}\right)$ and household composition $(2-6, \geq 7)$.

Although children $0-5$ and 6-23 months of age have predominantly different feeding practices, analyses for the two age groups were merged because age was not a significant effect modifier for indicators examined in predicting stunting. Multiple logistic regression analyses were used to examine the association between the risk of stunting and WASH practices adjusting for potential confounders. Stunting was included as the dependent variable, and household sanitation facilities, source of drinking water and reported personal hygiene practices as the independent variables, together with the potential confounding factors.

Confounding factors included the major determinants of child stunting based on UNICEF's conceptual framework. ${ }^{17} 18$ These were associated with each WASH indicator in the bivariate analyses using the $\chi^{2}$ test $(\mathrm{p}<0.05)$. The interactions between household sanitation facilities, source of drinking water and personal hygiene were created to examine the synergistic effects of WASH indicators on the risk of child stunting. The OR and corresponding $95 \%$ CIs were estimated with statistical significance defined as $\mathrm{p}<0.05$. All analyses were performed using STATA V.13.0 (Stat Corp, College Station, Texas, USA).

\section{RESULTS}

\section{National Family Health Survey}

The mean $( \pm \mathrm{SE})$ age of children in the analysis was $11.5 \pm 0.05$ months and $52 \%$ were male (table 1 ). Approximately $41 \%$ were stunted, $27 \%$ were wasted and $15 \%$ were reported to have had diarrhoea in the past 2 weeks. The mean $( \pm \mathrm{SE})$ age of the mothers of

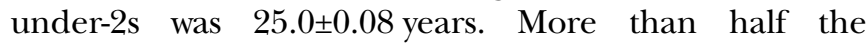


Table 1 Characteristics of children $0-23$ months included in the sample

\begin{tabular}{|c|c|c|c|}
\hline & NFHS* & HUNGaMAt & CNSM¥ \\
\hline$N$ & 10364 & 34639 & 1282 \\
\hline \multicolumn{4}{|l|}{ Child characteristics } \\
\hline Age, months (mean $\pm S E)$ & $11.5 \pm 0.05$ & $11.7 \pm 0.04$ & $11.0 \pm 0.24$ \\
\hline Male (\%) & 52 & 52 & 56 \\
\hline \multicolumn{4}{|l|}{ Birth order (\%) } \\
\hline $1-3$ & 71 & 76 & 93 \\
\hline$\geq 4$ & 29 & 24 & 7 \\
\hline Stunted height-for-age z-score, $<-2(\%) \S$ & 41 & 50 & 25 \\
\hline Wasted weight-for-height z-score, $<-2(\%) \S$ & 27 & 16 & 17 \\
\hline Had diarrhoea at least once in the past week(s) (\%) & 15 & 41 & 30 \\
\hline Breast feeding started within $1 \mathrm{~h}$ of birth (\%) & 22 & 42 & 67 \\
\hline \multicolumn{4}{|l|}{ Maternal characteristics } \\
\hline Age, year $($ mean $\pm S E)$ & $25.0 \pm 0.08$ & $26.8 \pm 0.04$ & $23.6 \pm 0.12$ \\
\hline \multicolumn{4}{|l|}{ Education (\%) } \\
\hline No schooling & 55 & 63 & 14 \\
\hline Primary school & 15 & 11 & 13 \\
\hline Secondary school & 27 & 14 & 57 \\
\hline >Secondary school & 3 & 12 & 15 \\
\hline Short stature, $<150 \mathrm{~cm}(\%)$ & 41 & - & 37 \\
\hline $\mathrm{BMl}<18.5 \mathrm{~kg} / \mathrm{m}^{2}(\%)$ & 44 & - & 40 \\
\hline \multicolumn{4}{|l|}{ Household characteristics } \\
\hline \multicolumn{4}{|l|}{ Family size (\%) } \\
\hline $2-3$ & 7 & 7 & 7 \\
\hline $4-6$ & 46 & 43 & 52 \\
\hline$\geq 7$ & 47 & 50 & 41 \\
\hline \multicolumn{4}{|l|}{ Place of defecation } \\
\hline Improved sanitation facility & 20 & - & 27 \\
\hline No toilet facility/bush/field & 77 & 83 & 65 \\
\hline \multicolumn{4}{|l|}{ Source of drinking water } \\
\hline Pipe water & 9 & 24 & 30 \\
\hline Other improved source ${ }^{\star *}$ & 74 & - & 57 \\
\hline
\end{tabular}

${ }^{*}$ Missing values existed in the NFHS sample, including the following: child diarrhoea $(n=5)$, breast feeding within $1 \mathrm{~h}$ of birth ( $\left.n=82\right)$, maternal height $(n=27)$, maternal BMI $(n=32)$.

†Missing values existing in the HUNGaMA sample, including the following: wasting $(n=2209)$, breast feeding within $1 \mathrm{~h}$ of birth $(n=389)$, maternal age $(n=186)$, maternal education $(n=438)$, household size $(n=257)$, source of drinking water $(n=3395)$.

¥Missing values existing in the CNSM sample, including the following: maternal age $(n=10)$, maternal education $(n=10)$, maternal height $(n=12)$, maternal BMI $(n=14)$.

§Estimated by using the 2006 WHO growth reference.

ףlmproved sanitation facilities included a flush toilet, piped sewer system, septic tank, flush to pit latrine, ventilated improved pit latrine, pit latrine with slab and composting toilet.

**Improved water sources other than piped water included a public tap or standpipe, tube well or borehole, protected dug well, protected spring and rainwater.

BMI, body mass index; CNSM, Comprehensive Nutrition Survey in Maharashtra; HUNGaMA, Hunger and Malnutrition Survey; NFHS, National Family Health Survey.

mothers had no education and $41 \%$ were short in stature $(<150 \mathrm{~cm})$. About $83 \%$ of the households had access to improved drinking water sources, and $\sim 9 \%$ had access to piped water. One-fifth of the households had improved sanitation facilities, whereas $77 \%$ had no toilet facility.

The presence of a household sanitation facility was associated with stunting among children aged 0-23 months. In a multivariate analysis, compared with open defecation, household access to toilet facility was associated with a $16 \%$ lower odds of being stunted, adjusting for all potential confounders $(\mathrm{OR}=0.84,95 \%$ CI 0.71 to 0.99 ; table 2). Household access to an improved drinking water source or piped water was not a predictor of child stunting. No interactions between household access to sanitation facilities and drinking water sources were observed (data not shown).

\section{Hunger and Malnutrition Survey}

The mean $( \pm$ SE) age of the children was $11.7 \pm 0.04$ months with both sexes equally represented (table 1 ). About a half $(50 \%)$ were stunted, $16 \%$ were wasted and $41 \%$ had had diarrhoea in the past week. The mean $( \pm \mathrm{SE})$ age of the mothers was $26.8 \pm 0.04$ years and approximately $63 \%$ had no education. About a quarter of the households (24\%) had access to piped water, whereas most of the households $(83 \%)$ had no toilet facility. 
Table 2 Crude and adjusted ORs of household water and sanitation conditions in relation to stunting for children who participated in the National Family Health Survey for 0-23 months ${ }^{\star}$

\begin{tabular}{|c|c|c|c|}
\hline & $\mathbf{N}$ & Crude OR (95\% CI) & Adjusted OR (95\% Cl) \\
\hline \multicolumn{4}{|l|}{ Household drinking water } \\
\hline Other & 9049 & 1.0 (Reference) & \multirow[t]{2}{*}{ Not retained in the final model } \\
\hline Piped & 1315 & $0.64(0.53$ to 0.76$)$ & \\
\hline \multicolumn{4}{|l|}{ Place of defecation } \\
\hline No facility/bush/field & 6635 & 1.0 (Reference) & 1.0 (Reference) \\
\hline Any toilet facility & 3729 & $0.53(0.46$ to 0.61$)$ & $0.84(0.71$ to 0.99$)$ \\
\hline \multicolumn{4}{|l|}{ Wealth index } \\
\hline Poorest & 2727 & 1.0 (Reference) & 1.0 (Reference) \\
\hline Poorer & 2617 & $0.78(0.67$ to 0.89$)$ & $0.86(0.74$ to 0.99$)$ \\
\hline Middle & 2390 & $0.66(0.56$ to 0.76$)$ & $0.83(0.71$ to 0.97$)$ \\
\hline Richer & 1764 & $0.46(0.39$ to 0.55$)$ & 0.71 (0.59 to 0.87$)$ \\
\hline Richest & 866 & $0.26(0.20$ to 0.33$)$ & $0.52(0.39$ to 0.69$)$ \\
\hline \multicolumn{4}{|l|}{ Social class } \\
\hline Other & 2962 & 1.0 (Reference) & 1.0 (Reference) \\
\hline Scheduled caste/tribe or other backward class & 7402 & $1.54(1.36$ to 1.74$)$ & 1.23 (1.07 to 1.42$)$ \\
\hline \multicolumn{4}{|l|}{ Maternal education } \\
\hline No schooling & 4973 & 1.0 (Reference) & 1.0 (Reference) \\
\hline Primary school & 1631 & $0.79(0.68$ to 0.91$)$ & $0.88(0.76$ to 1.02$)$ \\
\hline Secondary school & 3425 & $0.49(0.43$ to 0.55$)$ & $0.65(0.56$ to 0.74$)$ \\
\hline >Secondary school & 334 & $0.25(0.17$ to 0.37$)$ & $0.43(0.29$ to 0.65$)$ \\
\hline \multicolumn{4}{|l|}{ Maternal height } \\
\hline$\geq 150 \mathrm{~cm}$ & 9276 & 1.0 (Reference) & 1.0 (Reference) \\
\hline$<150 \mathrm{~cm}$ & 1087 & $1.70(1.53$ to 1.89$)$ & $1.59(1.43 \pm 1.78)$ \\
\hline \multicolumn{4}{|l|}{ Maternal age } \\
\hline$\geq 30$ & 2256 & 1.0 (Reference) & 1.0 (Reference) \\
\hline$<20$ & 1087 & $0.89(0.73$ to 1.07$)$ & $0.93(0.76$ to 1.14$)$ \\
\hline $20-29$ & 7020 & $0.74(0.65$ to 0.85$)$ & $0.85(0.74$ to 0.98$)$ \\
\hline \multicolumn{4}{|l|}{ Frequency of ANC visit during pregnancy } \\
\hline Less than 3 times & 5395 & 1.0 (Reference) & \multirow[t]{2}{*}{ Not retained in the final model } \\
\hline$\geq 3$ times & 4869 & $0.67(0.60$ to 0.75$)$ & \\
\hline \multicolumn{4}{|l|}{ Maternal dietary intake } \\
\hline Consumed $<4$ food groups a week $\ddagger$ & 6362 & 1.0 (Reference) & \multirow[t]{2}{*}{ Not retained in the final model } \\
\hline Consumed $\geq 4$ food groups a week $\ddagger$ & 3980 & $0.79(0.70$ to 0.88$)$ & \\
\hline \multicolumn{4}{|l|}{ Birth order } \\
\hline$\geq 5$ & 1822 & 1.0 (Reference) & \multirow[t]{3}{*}{ Not retained in the final model } \\
\hline$\overline{1-2}$ & 5615 & $0.66(0.57$ to 0.76$)$ & \\
\hline $3-4$ & 2926 & $0.79(0.68$ to 0.92$)$ & \\
\hline \multicolumn{4}{|l|}{ Initiation of breast feeding } \\
\hline After $1 \mathrm{~h}$ & 7025 & 1.0 (Reference) & \multirow[t]{2}{*}{ Not retained in the final model } \\
\hline Within $1 \mathrm{~h}$ of birth & 3239 & $0.90(0.80$ to 1.01$)$ & \\
\hline \multicolumn{4}{|l|}{ Complementary feeding practices } \\
\hline $\begin{array}{l}\text { Not fed a minimum number of times and the appropriate } \\
\text { number of the food groupt }\end{array}$ & 7313 & 1.0 (Reference) & 1.0 (Reference) \\
\hline $\begin{array}{l}\text { Fed a minimum number of times and the appropriate } \\
\text { number of the food group }\end{array}$ & 3050 & $1.16(1.00$ to 1.35$)$ & $1.50(1.28$ to 1.76$)$ \\
\hline $\begin{array}{l}\text { *Missing values for all indicators were less than } 3 \% \text {. } \\
\text { †Appropriate number of food groups including three or more food } \mathrm{g} \\
\text { non-breastfed children; the minimum number of times is defined as } \\
\text { times a day for breastfed children } 9-23 \text { months old. } \\
\text { fFood groups include milk and curd, pulse or beans, dark green le } \\
\text { ANC, antenatal care. }\end{array}$ & $\begin{array}{l}\text { for brea } \\
\text { st twice } \\
\text { getables }\end{array}$ & $\begin{array}{l}\text { a day for breastfed infar } \\
\text {, fruits, eggs, fish, chick }\end{array}$ & $\begin{array}{l}\text { more food groups for } \\
\text { s } 6-8 \text { months old and at least three } \\
\text { or meat. }\end{array}$ \\
\hline
\end{tabular}

Having a toilet facility at home was associated with a $16 \%$ reduced odds of being stunted among children aged 0-23 months, after adjusting for all potential confounders (OR=0.84, 95\% CI 0.78 to 0.91 ; table 3$)$. Household access to a piped water source was not associated with stunting. There were no synergistic effects of household sanitation and water supply on child stunting.

The mother's/caregiver's reported hygiene practices appeared to predict the risk of child stunting. In the 
Table 3 Crude and adjusted ORs of household water and sanitation conditions and personal hygiene in relation to stunting for children who participated in the Hunger and Malnutrition Survey by age group*

\begin{tabular}{|c|c|c|c|}
\hline & $\mathbf{N}$ & Crude OR (95\% Cl) & Adjusted OR (95\% Cl) \\
\hline \multicolumn{4}{|l|}{ Household drinking water source } \\
\hline Other & 23513 & 1.0 (Reference) & \multirow[t]{2}{*}{ Not retained in the final model } \\
\hline Piped & 7731 & $0.84(0.79$ to 0.9$)$ & \\
\hline \multicolumn{4}{|l|}{ Place of defecation } \\
\hline No facility/bush/field & 28457 & 1.0 (Reference) & 1.0 (Reference) \\
\hline Any toilet facility & 6022 & $0.62(0.58$ to 0.67$)$ & $0.84(0.78$ to 0.91$)$ \\
\hline \multicolumn{4}{|c|}{ Mother's/caregiver's practice of washing hands with soap after defecation } \\
\hline No & 28001 & 1.0 (Reference) & 1.0 (Reference) \\
\hline Yes & 6638 & $0.68(0.64$ to 0.73$)$ & $0.86(0.80$ to 0.93$)$ \\
\hline \multicolumn{4}{|l|}{ Household ownership of durable assets $†$} \\
\hline Owning $<2$ items & 14755 & 1.0 (Reference) & 1.0 (Reference) \\
\hline Owning $\geq 2$ items & 19560 & $0.72(0.68$ to 0.76$)$ & $0.89(0.84$ to 0.95$)$ \\
\hline \multicolumn{4}{|l|}{ Religion } \\
\hline Other & 5046 & 1.0 (Reference) & \multirow[t]{2}{*}{ Not retained in the final model } \\
\hline Hindu & 29581 & $0.92(0.85$ to 0.99$)$ & \\
\hline \multicolumn{4}{|l|}{ Social class } \\
\hline Other & 21241 & 1.0 (Reference) & 1.0 (Reference) \\
\hline Scheduled caste/tribe or other & 13386 & $1.32(1.25$ to 1.4$)$ & $1.21(1.14$ to 1.28$)$ \\
\hline \multicolumn{4}{|l|}{ backward class } \\
\hline \multicolumn{4}{|l|}{ Maternal education } \\
\hline No schooling & 20566 & 1.0 (Reference) & 1.0 (Reference) \\
\hline Primary school & 1119 & 0.79 (0.68 to 0.91$)$ & $0.83(0.71$ to 0.96$)$ \\
\hline Secondary school & 7949 & 0.65 (0.61 to 0.7$)$ & 0.72 (0.67 to 0.77$)$ \\
\hline >Secondary school & 4567 & $0.40(0.37$ to 0.43$)$ & $0.49(0.45$ to 0.54$)$ \\
\hline \multicolumn{4}{|l|}{ Maternal age } \\
\hline$\geq 30$ & 9394 & 1.0 (Reference) & \multirow[t]{3}{*}{ Not retained in the final model } \\
\hline$<20$ & 954 & $0.88(0.75$ to 1.03$)$ & \\
\hline $20-29$ & 24291 & $0.82(0.77$ to 0.87$)$ & \\
\hline \multicolumn{4}{|c|}{ Utilised ICDS's health check-up services for their child } \\
\hline No & 24327 & 1.0 (Reference) & \multirow[t]{2}{*}{ Not retained in the final model } \\
\hline Yes & 10093 & $0.90(0.85 \pm 0.95)$ & \\
\hline \multicolumn{4}{|l|}{ Birth order } \\
\hline$\geq 5$ & 4134 & 1.0 (Reference) & \multirow[t]{3}{*}{ Not retained in the final model } \\
\hline $1-2$ & 20166 & $0.74(0.68$ to 0.81$)$ & \\
\hline $3-4$ & 10337 & 0.85 (0.77 to 0.93$)$ & \\
\hline \multicolumn{4}{|l|}{ Initiation of breast feeding } \\
\hline After $1 \mathrm{~h}$ & 18839 & 1.0 (Reference) & 1.0 (Reference) \\
\hline Within $1 \mathrm{~h}$ of birth & 15411 & $0.78(0.74$ to 0.82$)$ & $0.88(0.82$ to 0.93$)$ \\
\hline \multicolumn{4}{|l|}{ Fed colostrum } \\
\hline No & 11038 & 1.0 (Reference) & 1.0 (Reference) \\
\hline Yes & 23312 & 0.77 (0.72 to 0.81$)$ & $0.89(0.83$ to 0.95$)$ \\
\hline \multicolumn{4}{|c|}{ Complementary feeding practices† (6-23 months) } \\
\hline Started before 6 months or after 8 months & 7577 & 1.0 (Reference) & Not retained in the final model \\
\hline Started $6-8$ months & 22230 & $0.98(0.92$ to 1.05$)$ & \\
\hline
\end{tabular}

multivariate analysis, the caregiver's reported practice of washing their hands with soap after defecation was associated with a $14 \%$ reduced risk of stunting among children aged $0-23$ months $(\mathrm{OR}=0.86$, $95 \%$ CI 0.80 to 0.93 ; table 3). Likewise, the caregiver's reported practice of washing their hands with soap before food was associated with a $15 \%$ lower odds of stunting among children aged $0-23$ months $(\mathrm{OR}=0.85,95 \%$ CI 0.76 to 0.94; data not shown).
There was a significant interaction between the mother's/caregiver's reported hygiene practices and household sanitation and drinking water conditions in their association with child stunting. The protective effect of the mother's/caregiver's reported practice of washing their hands with soap before food against child stunting was stronger among households with access to piped water $(\mathrm{OR}=0.77,95 \%$ CI 0.66 to 0.90 vs $\mathrm{OR}=0.89$, $95 \%$ CI 0.80 to 0.99 , interaction term $\mathrm{p}<0.05$; table 4 ). 
Table 4 Crude and adjusted ORs of household sanitation conditions and personal hygiene practices in relation to stunting for children aged 0-23 months who participated in the Hunger and Malnutrition Survey by household access to piped water

\begin{tabular}{|c|c|c|c|c|c|c|}
\hline & \multicolumn{3}{|c|}{ No access to piped water } & \multicolumn{3}{|c|}{ Having access to piped water } \\
\hline & $\mathbf{N}$ & Crude OR (95\% Cl) & Adjusted OR (95\% Cl) & $\mathbf{N}$ & Crude OR (95\% Cl) & Adjusted OR (95\% Cl) \\
\hline \multicolumn{7}{|l|}{ Place of defecation } \\
\hline No facility/bush/field & 20125 & 1.0 (Reference) & 1.0 (Reference) & 5506 & 1.0 (Reference) & 1.0 (Reference) \\
\hline Any toilet facility & 3289 & 0.66 (0.60 to 0.72$)$ & 0.85 (0.77 to 0.94$)$ & 2176 & 0.56 (0.49 to 0.64$)$ & 0.77 (0.66 to 0.91$)$ \\
\hline \multicolumn{7}{|c|}{ Mother's/caregiver's reported practice of washing hands with soap before meal } \\
\hline No & 21346 & 1.0 (Reference) & 1.0 (Reference) & 6001 & 1.0 (Reference) & 1.0 (Reference) \\
\hline Yes & 2167 & 0.74 (0.66 to 0.82$)$ & 0.89 (0.80 to 0.99$)$ & 1730 & $0.61(0.53$ to 0.70$)$ & 0.77 (0.66 to 0.90$)$ \\
\hline \multicolumn{7}{|c|}{ Household ownership of durable assets $\dagger$} \\
\hline Owning $<2$ items & 10497 & 1.0 (Reference) & 1.0 (Reference) & 2721 & 1.0 (Reference) & 1.0 (Reference) \\
\hline Owning $\geq 2$ items & 12820 & $0.75(0.71$ to 0.80$)$ & $0.90(0.84$ to 0.96$)$ & 4912 & 0.64 (0.57 to 0.73$)$ & 0.84 (0.74 to 0.96$)$ \\
\hline \multicolumn{7}{|l|}{ Social class } \\
\hline Other & 14148 & 1.0 (Reference) & 1.0 (Reference) & 4918 & 1.0 (Reference) & 1.0 (Reference) \\
\hline $\begin{array}{l}\text { Scheduled caste/tribe or other } \\
\text { backward class }\end{array}$ & 9356 & $1.34(1.25$ to 1.43$)$ & $1.23(1.15$ to 1.32$)$ & 2810 & $1.29(1.15$ to 1.46$)$ & $1.16(1.02$ to 1.32$)$ \\
\hline \multicolumn{7}{|l|}{ Maternal education } \\
\hline No schooling & 14683 & 1.0 (Reference) & 1.0 (Reference) & 3623 & 1.0 (Reference) & 1.0 (Reference) \\
\hline Primary school & 2708 & 0.79 (0.67 to 0.95$)$ & 0.83 ( 0.70 to 0.99$)$ & 880 & $0.96(0.68$ to 1.36$)$ & $1.02(0.71$ to 1.46$)$ \\
\hline Secondary school & 3374 & 0.68 (0.63 to 0.73 ) & 0.73 (0.67 to 0.80$)$ & 1332 & $0.65(0.57$ to 0.75$)$ & 0.72 (0.62 to 0.83 ) \\
\hline >Secondary school & 2462 & $0.41(0.37$ to 0.46$)$ & 0.49 (0.44 to 0.55$)$ & 1773 & $0.40(0.34$ to 0.47$)$ & 0.51 (0.43 to 0.61$)$ \\
\hline \multicolumn{7}{|l|}{ Maternal age } \\
\hline$\geq 30$ & 6487 & 1.0 (Reference) & Not retained in the final model & 1786 & 1.0 (Reference) & Not retained in the final model \\
\hline$<20$ & 668 & 0.93 (0.76 to 1.13$)$ & & 182 & 0.75 (0.52 to 1.08$)$ & \\
\hline $20-29$ & 16241 & $0.84(0.78$ to 0.90$)$ & & 5715 & 0.81 (0.71 to 0.93 ) & \\
\hline \multicolumn{7}{|c|}{ Utilised ICDS's health check-up service for their child } \\
\hline No & 17010 & 1.0 (Reference) & Not retained in the final model & 4850 & 1.0 (Reference) & Not retained in the final model \\
\hline Yes & 6400 & 0.95 (0.89 to 1.02$)$ & & 2793 & 0.85 (0.75 to 0.95$)$ & \\
\hline \multicolumn{7}{|l|}{ Birth order } \\
\hline$\geq 5$ & 2859 & 1.0 (Reference) & Not retained in the final model & 648 & 1.0 (Reference) & Not retained in the final model \\
\hline $1-2$ & 13111 & 0.80 (0.72 to 0.88$)$ & & 5190 & 0.59 (0.47 to 0.72$)$ & \\
\hline $3-4$ & 7412 & 0.86 (0.77 to 0.96$)$ & & 1842 & $0.83(0.66$ to 1.05$)$ & \\
\hline \multicolumn{7}{|l|}{ Initiation of breast feeding } \\
\hline After $1 \mathrm{~h}$ & 13351 & 1.0 (Reference) & 1.0 (Reference) & 3616 & 1.0 (Reference) & Not retained in the final model \\
\hline Within $1 \mathrm{~h}$ of birth & 9920 & 0.82 (0.77 to 0.88$)$ & 0.90 (0.83 to 0.97$)$ & 4010 & $0.71(0.63$ to 0.80$)$ & \\
\hline \multicolumn{7}{|l|}{ Fed colostrum } \\
\hline No & 7993 & 1.0 (Reference) & 1.0 (Reference) & 2054 & 1.0 (Reference) & Not retained in the final model \\
\hline Yes & 15350 & $0.82(0.77$ to 0.87$)$ & 0.91 (0.84 to 0.99$)$ & 5585 & 0.69 (0.61 to 0.79$)$ & \\
\hline
\end{tabular}

†Household durable assets include a television, radio, mobile phone, two-wheeler, tractor and cycle. 
In addition, the inverse association between the mother's/caregiver's reported practices of washing their hands with soap after defecation and stunting was stronger among households with access to toilet facility ( $\mathrm{OR}=0.73,95 \%$ CI 0.61 to 0.88 vs $\mathrm{OR}=0.88,95 \%$ CI 0.80 to 0.98 ; data not shown).

\section{Comprehensive Nutrition Survey in Maharashtra}

The mean $( \pm \mathrm{SE})$ age of the children was 11.0 \pm 0.24 months and about $56 \%$ were male (table 1 ). About a quarter $(25 \%)$ of the children were stunted, $17 \%$ were wasted and $30 \%$ had had diarrhoea in the past 2 weeks. The mean $( \pm \mathrm{SE})$ age of the mothers was $23.6 \pm 0.12$ years and $14 \%$ had no education. Approximately $87 \%$ of the households had improved sources of drinking water, and about $30 \%$ had access to piped water. Twenty-seven per cent of the households had access to improved sanitation facilities.

In multivariate analysis, household access to toilet facility was associated with a $39 \%$ reduced odds of being stunted among children aged 0-23 months, after adjusting for all potential confounders $(\mathrm{OR}=0.61,95 \%$ CI 0.44 to 0.85 ; table 5 ). Household access to an improved water source and piped water did not predict child stunting.

\section{DISCUSSION}

We report here the association between child stunting and household access to improved sanitation and drinking water source and personal hygiene in India, based on large survey data sets representative at national, state and district levels. Notably, household access to toilet facility was associated with a $16-39 \%$ reduced odds of stunting among children aged 0-23 months. On the other hand, household access to an improved source of drinking water or piped water in particular was not a predictor of stunting. The mother's/caregiver's reported practices of washing their hands with soap either before a meal or after defecation was associated with a $15 \%$ reduced risk of stunting.

Overall, our results of the inverse association between stunting and household access to toilet facility tend to confirm the findings of previous non-randomised research carried out in different parts of the world. ${ }^{19-22}$ Using data from multiple countries in Africa, Asia and Latin America, Esrey ${ }^{19}$ showed that improved sanitation was associated with a 0.06-0.62 and 0.26-0.65 increment in HAZ in children living in rural and urban areas, respectively. ${ }^{19}$ Similarly, in a cross-sectional analysis of 171 Demographic and Health Surveys conducted worldwide (India not included), access to improved sanitation was shown to be associated with a $27 \%$ lower risk of child stunting. ${ }^{20}$ Recently, in an ecological analysis, Spears $e t a l^{11}$ found that differences in open defecation could statistically account for $35-55 \%$ of the average difference in stunting between districts in India. The findings of our analysis, based on three large survey data sets collected at the household level, reinforce the notion that poor sanitation may indeed greatly increase the likelihood of child stunting in rural India where open defecation is pervasive and the burden of child stunting is massive.

It is evident that children become more affected by environmental contamination as they start crawling,

Table 5 Crude and adjusted ORs of household water and sanitation conditions in relation to stunting for children who participated in the Comprehensive Nutrition Survey in Maharashtra for under-2s*

\begin{tabular}{|c|c|c|c|}
\hline & $\mathbf{N}$ & Crude OR (95\% CI) & Adjusted OR (95\% Cl) \\
\hline \multicolumn{4}{|c|}{ Household drinking water source } \\
\hline Other & 913 & 1.0 (Reference) & \multirow[t]{2}{*}{ Not retained in the final mode } \\
\hline Piped & 369 & $0.86(0.60$ to 1.23$)$ & \\
\hline \multicolumn{4}{|l|}{ Place of defecation } \\
\hline No facility/bush/field & 790 & 1.0 (Reference) & 1.0 (Reference) \\
\hline Any toilet facility & 492 & $0.57(0.41$ to 0.78$)$ & $0.61(0.44$ to 0.85$)$ \\
\hline \multicolumn{4}{|l|}{ Wealth index } \\
\hline Poorest & 392 & 1.0 (Reference) & \multirow[t]{5}{*}{ Not retained in the final mode } \\
\hline Poorer & 415 & $1.00(0.68$ to 1.46$)$ & \\
\hline Middle & 306 & $1.04(0.70$ to 1.57$)$ & \\
\hline Richer & 133 & $0.75(0.43$ to 1.31$)$ & \\
\hline Richest $†$ & 36 & $0.70(0.25$ to 1.93$)$ & \\
\hline \multicolumn{4}{|l|}{ Maternal education } \\
\hline No schooling & 181 & 1.0 (Reference) & \multirow[t]{4}{*}{ Not retained in the final model } \\
\hline Primary school & 143 & $0.82(0.47$ to 1.4$)$ & \\
\hline Secondary school & 743 & $0.70(0.46$ to 1.06$)$ & \\
\hline >Secondary school & 215 & $0.58(0.31$ to 1.11$)$ & \\
\hline \multicolumn{4}{|l|}{ Maternal height } \\
\hline$\geq 150 \mathrm{~cm}$ & 790 & 1.0 (Reference) & 1.0 (Reference) \\
\hline$<150 \mathrm{~cm}$ & 480 & 2.30 (1.69 to 3.13$)$ & 2.22 (1.63 to 3.01$)$ \\
\hline
\end{tabular}

${ }^{*}$ Missing values for all indicators were less than $3 \%$.

tOR $(95 \% \mathrm{Cl})$ for children $0-5$ months was dropped due to the small sample size. 
walking, exploring and putting objects in their mouths, which increases the risk of ingesting faecal bacteria from both human and animal sources. This leads to repeated bouts of diarrhoea and intestinal worms, which in turn deteriorates the nutritional status of children. ${ }^{23}$ Importantly, growing evidence suggests that a key cause of child undernutrition is a subclinical disorder of the small intestine known as environmental enteropathy, which in turn is caused by faecal bacteria ingested in large quantities by young children living in conditions of poor sanitation and hygiene. ${ }^{24}$ This hypothesis makes addressing the issue of sanitation even more critical.

Household access to an improved source of drinking water or piped water was not associated with child stunting. This corroborates earlier findings from nonrandomised studies which indicate that the potential effects of improved water supply on child linear growth tend to be much smaller than those of improved sanitation. ${ }^{19}$ This lack of association in our analysis may be explained by the current predominant use of an improved drinking water source in India, reflecting source only, not on water safety. NFHS and CNSM showed that $\sim 83 \%$ and $\sim 74 \%$ of the households in rural areas, respectively, have access to improved drinking water sources. ${ }^{2}{ }^{13}$ About a quarter of the households reported having water piped into the dwelling, plot or yard. $^{2}{ }^{13}$ Although household access to piped water was significantly associated with stunting in bivariate analyses, it was not a predictor of stunting in multivariate analysis adjusting for all potential confounders.

Our results indicated no significant interactions between household access to improved water and sanitation. Overall, there is mixed evidence on the synergistic effects of water and sanitation on child linear growth. ${ }^{19} 2125$ In a cross-sectional, multicountry study, Esrey $^{19}$ noted that the positive association between improved sanitation and child linear growth was enhanced by household access to improved water supply. Similarly, in a longitudinal study in Peru, Checkley $e t a l^{21}$ found that the positive association between improved water sources and child linear growth existed only when it was accompanied by improved sanitation and water storage practices. In contrast, no synergistic effects of water and sanitation were found in a large prospective cohort study in Sudan. ${ }^{25}$ Therefore, further research is required to determine if improved household water supply and its handling and storage, and sanitation have additive or synergistic effects on child linear growth. It should also be noted that the major pathways of faecal-oral transmission of bacteria may be different for infants compared with older people. Infants who are breast fed receive the majority of their fluid and nutrient requirements from breast milk and consume little amount of drinking water. Thus, the amount of bacteria they ingest from contaminated water may be small compared with other things babies put in their mouths during developmental exploration.
Few studies have explored the association between the mother's/caregiver's personal hygiene practices and child stunting in India. We found that mothers/caregivers who reported washing their hands with soap either before a meal or after defecation had a lower association with stunted children. This corresponds with the findings from a community-based cross-sectional study conducted in the rural State of Madhya Pradesh in which maternal hygiene practices were significantly associated with child undernutrition. ${ }^{26}$ Our findings also suggest that the protective effects of the mother's/caregiver's reported personal hygiene practices were stronger when it was accompanied by an improved household access to piped water and toilet facility. Clearly, efforts to improve hand washing practices of both mothers/caregivers and children themselves are essential to prevent diarrhoea and other infections among children, which in turn may contribute to the reduction of stunting. These efforts should be accompanied by concrete actions to enhance household water and sanitation conditions. Further research is required to examine the impact of improved personal hygiene practices on child growth, especially as part of a multisectoral and convergent approach to effectively address child stunting.

The limitations to this study need to be considered. We analysed cross-sectional data, so a causal association between improved WASH practices and reduced likelihood of stunting cannot be established. The mother's/ caregiver's reported personal hygiene practices were determined based on self-reported data which may reflect on improved knowledge as opposed to actual practice and may lead to validity problems. Moreover, the HUNGaMA survey only inquired whether the mother/caregiver was using soap for washing hands before meals. It was not clear whether the mother/caregiver washed hands before eating her own meal or feeding her child. While NFHS and CNSM used similar classifications for the source of drinking water and sanitation facilities, the HUNGaMA survey used a different categorisation. Thus, households having access to an improved source of drinking water and sanitation facilities could not be determined using the HUNGaMA data. Data on personal hygiene were not collected from NFHS and only the proportion of mothers/caregivers reporting that they washed their hands with soap was determined in CNSM. Although an important variable to consider, the birth weight of children was not included in the multivariate analysis, as the information was collected from a small proportion of the sample. However, we did control for maternal height, BMI, dietary intake and other relevant factors, which are strong predictors of child birth weight. Despite these limitations, assessing the WASH association with child stunting using large representative survey data sets coming from the local context is a critical step in strengthening the relevant evidence base and developing multisectoral interventions for optimal child growth. 
In conclusion, this analysis revealed that household sanitation and the mother's/caregiver's reported personal hygiene practices are strong predictors of child stunting in India. This reinforces the growing evidence of the effects of WASH practices on child linear growth. Large-scale randomised effectiveness trials of toilet provision (and use) and reported hand washing at critical times, which include environmental enteropathy and child growth as outcomes, are warranted to go beyond association in order to estimate causality. However, this suggests the need for different programmatic responses by governments and development partners. Optimising nutrition outcomes for young children now requires a framework that is broader than nutrition-specific interventions alone. India's vulnerable children and mothers need to benefit from additional, well-targeted nutrition-sensitive interventions, especially leading up to and during the first 1000 days. Children and mothers need basic WASH provision and behaviours to survive, grow and thrive.

\section{Author affiliations}

${ }^{1}$ Child Development and Nutrition Programme, United Nations Children's Fund, New Delhi, India

${ }^{2}$ Water, Sanitation and Hygiene Programme, United Nations Children's Fund, Jakarta, Indonesia

${ }^{3}$ Regional Office for South Asia, United Nations Children's Fund, Kathmandu, Nepal

${ }^{4}$ Water, Sanitation and Hygiene Programme, United Nations Children's Fund, New Delhi, India

${ }^{5}$ International Development Research Centre, New Delhi, India

Acknowledgements The authors wish to thank Dr Francis Odhiambo for his insightful comments on the manuscripts and Ms Nina Badgaiyan on her support in data analysis.

Contributors JHR and AAC conceptualised, designed and wrote the paper. JHR and BB analysed the data sets. JHR, VMA and SJC wrote the paper. All authors read the manuscript, made a substantial contribution to the revision and approved the final manuscript.

Funding This analysis was funded by the International Development Research Centre.

Competing interests None.

Disclaimer The opinions expressed are those of the authors and editors and do not necessarily reflect the views of the institutions that they are affiliated with.

Provenance and peer review Not commissioned; externally peer reviewed.

Data sharing statement No additional data are available.

Open Access This is an Open Access article distributed in accordance with the Creative Commons Attribution Non Commercial (CC BY-NC 4.0) license, which permits others to distribute, remix, adapt, build upon this work noncommercially, and license their derivative works on different terms, provided the original work is properly cited and the use is non-commercial. See: http:// creativecommons.org/licenses/by-nc/4.0/

\section{REFERENCES}

1. De Onis M, Dewey KG, Borghi E, et al. The World Health Organization's global target for reducing child stunting by 2025 : rationale and proposed actions. Matern Child Nutr 2013; 9(Supple 2):6-26.

2. International Institute for Population Sciences (IIPS) and Macro International. National Family Health Survey (NFHS-3) 2005-6. Mumbai: IIPS, 2007.

3. Black RE, Victora CG, Walker SP, et al. Maternal and child undernutrition and overweight in low-income and middle-income countries. Lancet 2013;382:427-51.

4. Victora CG, Adair L, Fall C, et al. Maternal and child undernutrition: consequences for adult health and human capital. Lancet 2008;371:340-57.

5. Ruel MT. The natural history of growth failure: importance of intrauterine and postnatal periods. In: Martorell R, Haschke F, eds. Nutrition and growth. Philadelphia, USA: Lippincott Williams and Wilkins, 2001:123-58.

6. Dewey KG, Adu-Afarwuah S. Systematic review of the efficacy and effectiveness of complementary feeding interventions in developing countries. Matern Child Nutr 2008;4(Suppl 1):24-85.

7. Victora CG, de Onis M, Hallal PC, et al. Worldwide timing of growth faltering: revisiting implications for interventions. Pediatrics 2010;125:e473-80.

8. Ngure FM, Reid BM, Humphrey $\mathrm{JH}$, et al. Water, sanitation, and hygiene (WASH), environmental enteropathy, nutrition, and early child development: making the links. Ann N Y Acad Sci 2014;1308:118-28.

9. World Bank. Environmental health and child survival: epidemiology, economics, experience. Washington DC: World Bank, 2008.

10. Dewey KG, Mayers DR. Early child growth: how do nutrition and infection interact? Matern Child Nutr 2011;7(Suppl 3):129-42.

11. Spears D, Ghosh A, Cumming O. Open defecation and childhood stunting in India: an ecological analysis of new data from 112 districts. PLOS ONE 2013;8:e73784.

12. The Naandi Foundation. The hunger and malnutrition survey report -2011. http://naandi.org/HungamaBKDec11LR.pdf (accessed 16 Feb 2014)

13. International Institute for Population Sciences (IIPS). Comprehensive nutrition survey in Maharashtra 2012. IIPS, 2012.

14. Gibson RS. Principles of nutritional assessment. New York, NY: Oxford University Press, 1990.

15. World Health Organization. WHO child growth standards: methods and development. Geneva, Switzerland: WHO, 2006.

16. World Health Organization and United Nations Children's Fund Joint Monitoring Programme for Water Supply and Sanitation. Types of drinking water and sanitation. http://www.wssinfo.org/definitionsmethods/watsan-categories/ (accessed 17 Feb 2014).

17. World Health Organization. Drinking Water. http://www.who.int/ water_sanitation_health/monitoring/water.pdf (accessed $17 \mathrm{Feb}$ 2014).

18. De Pee S, Bloem MW. Assessing and communicating the impact of nutrition and health programs. In: Semba RD, Bloem MW, eds. Nutrition and health in developing countries. Totowa, NJ: Human Press, 2001:483-506.

19. Esrey SA. Water, waste, and well-being: a multi-country study. $A m \mathrm{~J}$ Epidemiol 1996;143:608-23.

20. Fink G, Gunther I, Hill K. The effect of water and sanitation on child health: evidence from the demographic and health surveys 1986-2007. Int J Epidemiol 2011;40:1196-204.

21. Checkley W, Gilman RH, Black RE, et al. Effect of water and sanitation on childhood health in a poor Peruvian peri-urban community. Lancet 2004;363:112-18.

22. Lin A, Arnold BF, Afreen S, et al. Household environmental conditions are associated with enteropathy and impaired growth in rural Bangladesh. Am J Trop Med Hyg 2013;89:130-7.

23. Prüss-üstün A, Bos R, Gore $\mathrm{F}$, et al. Safe water, better health: costs, benefits and sustainability of interventions to protect and promote health. Geneva: World Health Organization, 2008.

24. Humphrey $\mathrm{JH}$. Child undernutrition, tropical enteropathy, toilets, and handwashing. Lancet 2009;374:1032-5.

25. Merchant AT, Jones C, Kiure A, et al. Water and sanitation associated with improved child growth. Eur J Clin Nutr 2003;57:1562-8.

26. Meshram II, Arlappa N, Balakrishna N, et al. Influence of feeding practices and associated factors on the nutritional status of infants in rural areas of Madhya Pradesh State, India. Asia Pac J Public Health 2013. Published 10 May 2013. doi:10.1177/ 1010539513486174 